\title{
Birth of a healthy child by a woman with inherited Xq duplications who had experienced stillbirths
}

\author{
Y. Dong1, S.C. Chen ${ }^{2}$, X.W. Yu' ${ }^{1}$ E. Fadlalla1, F. Jin ${ }^{2}$ and R.Z. Liu ${ }^{1}$ \\ ${ }^{1}$ Center for Reproductive Medicine, Center for Prenatal Diagnosis, \\ First Hospital, Jilin University, Changchun, China \\ ${ }^{2}$ Center of Reproductive Medicine, Women's Hospital, \\ College of Medicine, Zhejiang University, Hangzhou, China \\ Corresponding author: R.Z. Liu \\ E-mail:1rz410@126.com
}

Genet. Mol. Res. 13 (2): 4573-4578 (2014)

Received May 29, 2013

Accepted October 1, 2013

Published June 17, 2014

DOI http://dx.doi.org/10.4238/2014.June.17.9

\begin{abstract}
A 23-year-old woman who had experienced repeated stillbirths, was found to carry an additional segment on the long arm of the $\mathrm{X}$ chromosome. Array comparative genomic hybridization (aCGH) confirmed the origin of the 2 duplications (about 17.11 $\mathrm{Mb})$. Thus, her karyotype was 46, X, dup (X) (q13.2-q21.1), dup(X) (q21.32-q22.1). We demonstrate that aCGH is a useful complementary tool to cytogenetic analysis for accurately determining banding. To our knowledge, this is the first case with normal apparently phenotype who inherited 2 duplications on Xq. Notably, after 2 stillbirths, she bore a healthy, normal female infant via natural pregnancy. Thus, a carrier of this karyotype can birth a phenotypically normal child.
\end{abstract}

Key words: Array comparative genomic hybridization; Duplication X; Inherited; Stillbirth 


\section{INTRODUCTION}

Stillbirth rates range from $0.5 \%$ in rich countries to $3.2 \%$ in southern Asia and subSaharan Africa (Stanton et al., 2006). Chromosome analysis, obstetric history, laboratory tests, and autopsy findings are generally used to investigate the cause of a stillbirth (Incerpi et al., 1998). About $15-25 \%$ of stillbirths are caused by genetic factors and up to $20 \%$ of stillborn babies with malformations have chromosomal abnormalities (Simpson and Acuna, 2011). Duplication of the X chromosome can be de novo or inherited (Aughton et al., 1993). X chromosomal duplication in males is associated with multiple congenital anomalies and developmental delays (Solomon et al., 2004; Cheng et al., 2005). However, its manifestations in females are varied and complex. Some females are normal, some only have short stature, and others have a variety of abnormalities (Armstrong et al., 2003).

Here, we describe a phenotypically normal female with inherited 2 partial duplications on the long arm of the $\mathrm{X}$ chromosome. Array comparative genomic hybridization (aCGH) confirmed the origin of the X duplications. After 2 stillbirths, she gave birth to a healthy female infant. To our best knowledge, this is the first repeated case of a woman with a normal phenotype bearing a baby via natural pregnancy with 2 duplications on the long arm of the $\mathrm{X}$ chromosome.

\section{MATERIAL AND METHODS}

\section{Patients}

The proposita was a 23-year-old Chinese woman who had twice experienced stillbirth. Her height was $162 \mathrm{~cm}$ and weight was $57.5 \mathrm{~kg}$. She is the third child of a non-consanguineous, healthy 50-year-old father and 54-year-old mother who had no adverse reproductive history. Her elder brother had fathered a phenotypically normal child, although another brother died only 10 minutes after his birth with multiple malformations.

Reproductive hormone levels of the proband, detected by an electrochemiluminescence immunoassay using a Elecsys ${ }^{\circledR} 2010$ Serum Chemistry Analyzer (Roche Diagnostics, Mannheim, Germany), were normal for: luteinizing hormone (LH), $4.01 \mathrm{mIU} / \mathrm{mL}$ (normal range $=2.4-12.6 \mathrm{mIU} / \mathrm{mL}$ ); estradiol $(\mathrm{E} 2), 33.17 \mathrm{pg} / \mathrm{mL}$ (normal range $=12.5-166 \mathrm{pg} / \mathrm{mL}$ ); progesterone (P), $0.905 \mathrm{ng} / \mathrm{ml}$ (normal range, 0.2-1.5 ng/mL); prolactin (PRL), $497 \mu \mathrm{IU} / \mathrm{mL}$ (normal range, $102-498 \mu \mathrm{IU} / \mathrm{mL}$ ); and testosterone $(\mathrm{T}), 1.18 \mathrm{ng} / \mathrm{mL}$ (normal range, $0.22-2.9 \mathrm{ng} /$ $\mathrm{mL})$, whereas follicle-stimulating hormone (FSH) was slightly lower $(6.27 \mathrm{mIU} / \mathrm{mL}$, normal range $=8.5-12.5 \mathrm{mIU} / \mathrm{mL}$ ). Normal uterus and ovaries were detected by ultrasonographic examination. Other laboratory tests conducted to investigate the causes of stillbirth were normal.

The pregnancy of the patient, 1 year after undergoing chromosome analysis, was conceived naturally. At 19 weeks of gestation, she had undergone prenatal screening and ultrasonographic examination with normal results. Then, she bore a female infant with a normal phenotype. At the time of writing this manuscript, her infant was 6 months old.

\section{Cytogenetic analysis and array comparative genomic hybridization (aCGH)}

Peripheral blood lymphocytes were cultured in lymphocyte culture medium (Yishengjun; BaiDi Bio-Technology, Guangzhou, China) at $37^{\circ} \mathrm{C}$ for $72 \mathrm{~h}$, followed by treatment 
with $50 \mu \mathrm{g} / \mathrm{mL}$ colchicine (Yishengjun) to arrest mitosis for $1 \mathrm{~h}$ before culture termination. Lymphocyte harvesting was performed by hypotension, fixation, trypsinization, and Giemsa banding (GTG-banding) (350-400 bands level). At least 20 metaphases were analyzed.

Sample genomic DNA was isolated from peripheral blood, using a DNA extraction kit such as the QIAGEN QIAamp DNA Blood Mini Kit. Control DNA was obtained directly from Promega (G1471/G1521). After that, around 50-400 ng of sample and control DNA were labeled with $\mathrm{Cy} 3$ and $\mathrm{Cy} 5$ fluorophores, respectively. Labeling mixes were combined and co-precipitated with COT Human DNA in preparation for hybridization on the microarray. A CytoChip with 3500 BAC DNA targets spaced at $\sim 1-\mathrm{Mb}$ intervals were produced in BlueGnome (Illumina). Labeled DNA were resuspended in hybridization buffer and hybridized to the CytoChip microarray area for $16-21 \mathrm{~h}$ at $47^{\circ} \mathrm{C}$. The hybridized fluorophores were then imaged on a scanner (InnoScan 710; INNOPSYS, France) and the resulting images of the Cy3 and Cy5 signals in TIFF format were read by the BlueFuse Multi analysis software (BlueGnome, UK). CytoChip BAC arrays can be scanned at $10-\mu \mathrm{m}$ resolution. The BlueFuse Multi software was used to complete analysis and reporting of regions of genomic copy number imbalance. The following criteria were used to make a diagnosis of a gain or loss according to the value of $\log _{2}(\mathrm{Cy} 5 / \mathrm{Cy} 3): 3$ or more adjacent probes changed in the same direction, if $\log _{2}(\mathrm{Cy} 5 / \mathrm{Cy} 3)>0.40$, the region was classified as repeated; if $\log _{2}(\mathrm{Cy} 5 / \mathrm{Cy} 3)<-0.40$, the region was classified as a deleted region $(0.40$ as the threshold).

\section{RESULTS}

Conventional cytogenetic analysis of the proband with GTG-banding revealed a chromosome number of 46, including 1 normal $\mathrm{X}$ chromosome and $1 \mathrm{X}$ with additional material on the long arm (Figure 1A). [Karyotype: 46, X, dup(X?q21)]. Her mother's karyotype was as the same as the proband, 46, X, dup(X?q21) (Figure 1B). However, the karyotypes of her father, elder brother, and husband were all normal with 46, XY. Figure 1C and D show the idiogram of duplicated Xq and a pedigree analysis of the family, respectively. No karyotype was analyzed for her deceased brother.

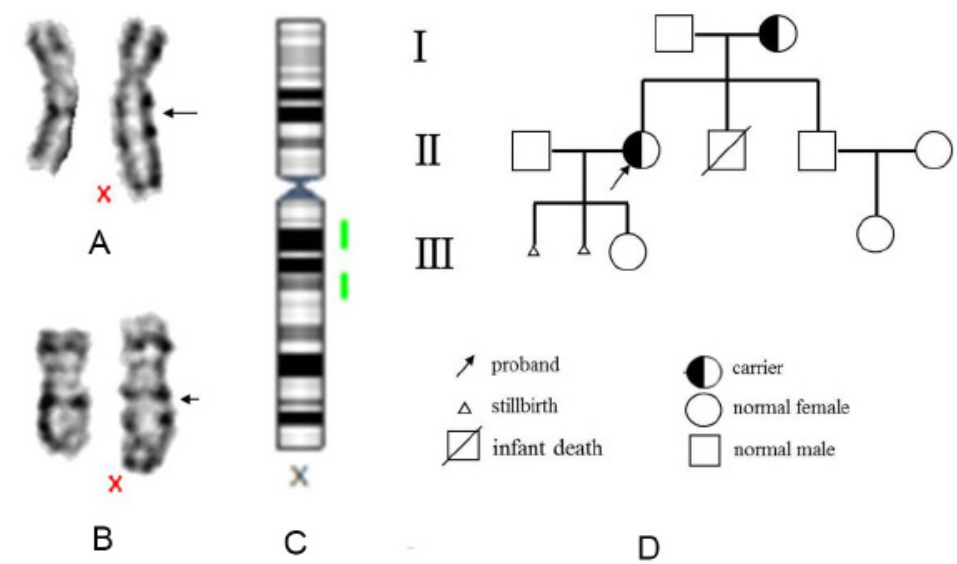

Figure 1. A. GTG-banded X chromosomes of the proposita. Normal homologue (left) and duplicated Xq (right); B. GTG-banded of X chomosomes of her mother; C. idiogram of duplicated Xq (Green on behalf of the two repeat regions); D. pedigree of the famility. 
Our aCGH results included 2 duplications on the long arm of the $\mathrm{X}$ chromosome that encompassed approximately $17.11 \mathrm{Mb}$ of the proband (Table 1, Figure 2). One duplication segment, from Xq13.2 to Xq21.1, encompassed approximately $9.43 \mathrm{Mb}$ that encoded 36 HGNC (Hugo Gene Nomenclature Committee) genes and 19 OMIM (Online Mendelian in Man) genes. Another duplication area that encoded 28 HGNC genes and 16 OMIM genes, from Xq21.32 to Xq22.1, encompassed approximately 7.67 Mb. Thus, Array CGH combining with G-banding showed that the karyotype of the proband is 46, X, dup (X) (q13.2-q21.1), $\operatorname{dup}(\mathrm{X})(\mathrm{q} 21.32-\mathrm{q} 22.1)$.

Table 1. Results by analysis CytoChip of the proband.
\begin{tabular}{lllllcrcc}
\hline Region & Start Cyto & End Cyto & Type & Chr & Start & End & Size (bp) & \% Included \\
\hline 1 & Xq13.2 & Xq21.1 & GAIN & X & $73,109,547$ & $82,541,761$ & $9,432,215$ & 100 \\
2 & Xq21.32 & Xq22.1 & GAIN & X & $93,081,153$ & $100,754,570$ & $7,673,417$ & 91.67 \\
\hline
\end{tabular}

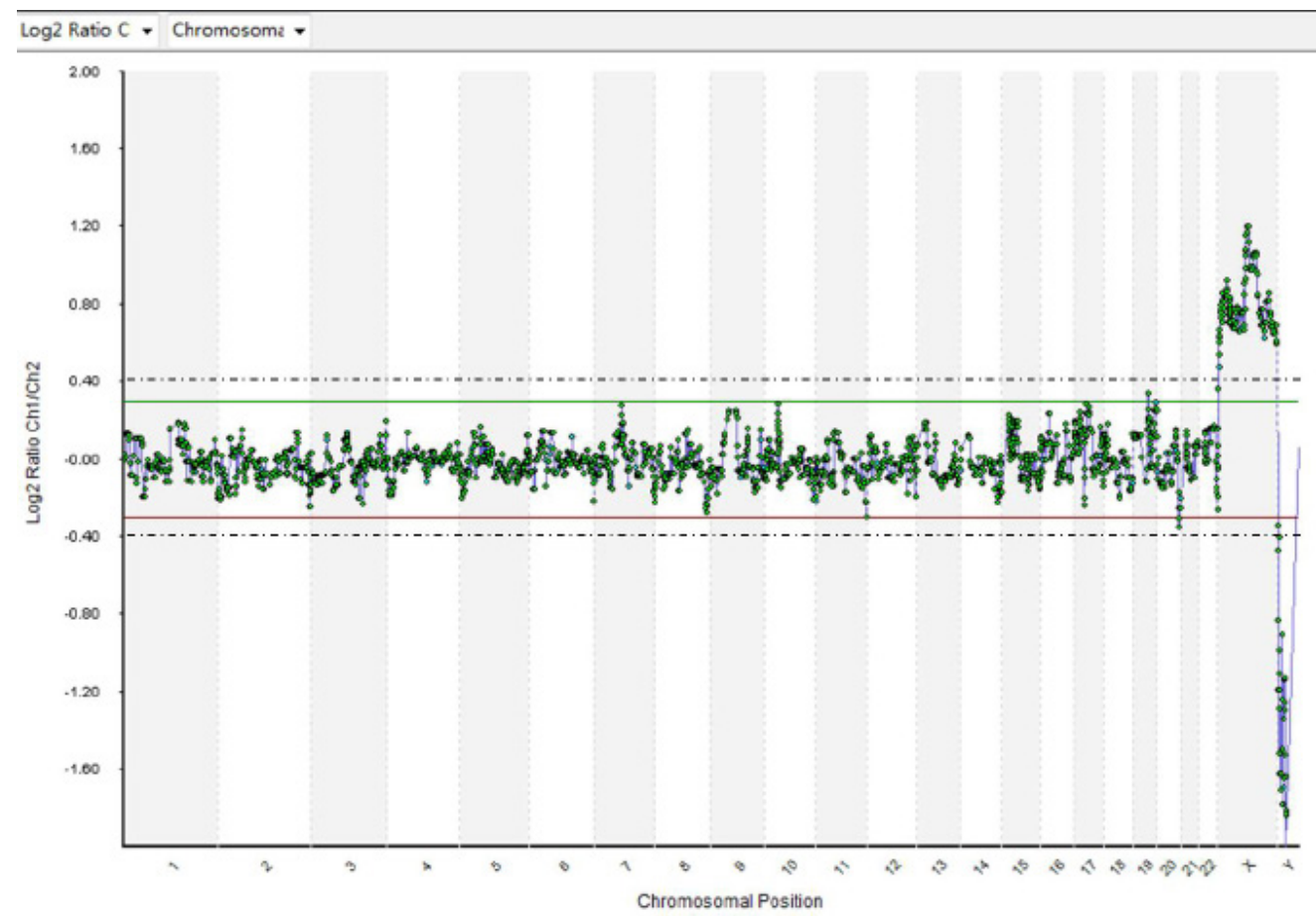

Figure 2. aCGH profile of all the chromosomes, with two duplications in $\mathrm{X}$ chromosome. Dotted lines represent threshold $=0.40 /-0.40$. If $\log _{2}(\mathrm{Cy} 5 / \mathrm{Cy} 3)>0.40$, the region as repeated, if $\log _{2}(\mathrm{Cy} 5 / \mathrm{Cy} 3)<-0.40$, the region as deletional region.

\section{DISCUSSION}

Duplication of the X chromosome can occur in both males and females. Reports frequently describe female patients with different repeated segments and different abnormal clin- 
ical phenotypes (Volletha et al., 2001; Kokalj Vokac et al., 2002; Burégio-Frota et al., 2010). These data suggest that the distribution of $\mathrm{X}$ chromosomal duplications in males and females is different, and duplications on Xq may result in a less severe abnormal phenotype than those on Xp (Zhang et al., 1997; Carrel et al., 1999). The severity of the abnormal phenotype is not only related to the location and size of the duplication, and the $\mathrm{X}$-inactivation pattern in different tissues should also be considered (Lachlan et al., 2004).

Females with structurally abnormal $\mathrm{X}$ chromosomes are predicted to be protected from genetic imbalance through preferential inactivation of the $\operatorname{dup}(\mathrm{X})$ chromosome and are usually phenotypically normal (Therman et al., 1980). To our knowledge, there have been no previous reports on a normal phenotype female with only stillbirth and 2 partial inherited duplications of Xq. More importantly, she later bore a phenotypically normal female infant.

According to the Database of Genomic Variants Archive and OMIM, genes in the $\mathrm{Xq13.2-Xq21.1} \mathrm{and} \mathrm{Xq21.32-Xq22.1} \mathrm{regions} \mathrm{do} \mathrm{not} \mathrm{include} \mathrm{well-known} \mathrm{genes} \mathrm{associated}$ with reproductive failure. We hypothesized that our current case has been a consequence of preferential inactivation of the dup $(\mathrm{X})$ and implied that the normal $\mathrm{X}$ chromosome was active. During prophase I of meiosis, the duplication segment can form a loop to allow homologous sequences to align. Additionally, asymmetric crossing over the loop may lead to the formation of the dicentric chromosome. In the early postzygotic period, the dicentric chromosome can undergo a breakage and create an unbalanced zygote that could have resulted in the 2 stillbirths of the proposita. However, when the duplication region can align with the homologous chromosome, the patient conceived naturally and bore a girl at 6 months with a normal phenotype. Her mother, of the same karyotype as the proband, gave birth to 2 phenotypically normal children and an abnormal son who died 10 min after delivery with unexplained reason. Considering her mother's reproductive history, this current karyotype of the 2 duplications of Xq13.2-q21.1 and Xq21.32-q22.1 can birth a phenotypically normal child. However, prenatal screening and diagnosis could be necessary.

In conclusion, our patient appears to be the first reported case that showed 2 inherited duplications on the long arm of X chromosome and had a normal phenotype female infant despite 2 previous stillbirths. The aCGH technique was used to precisely define the breakpoints of the 2 unknown chromosomal duplications.

\section{ACKNOWLEDGMENTS}

We are grateful to the patient and her family members for participating in this study. We also thank the staff at the Cytogenetic Laboratory for their excellent work. Research supported by funds from the National Population and Family Planning Commission of China (\#2011-GJKJS-07).

\section{REFERENCES}

Armstrong L, McGowan-Jordan J, Brierley K and Allanson JE (2003). De novo dup(X)(q22.3q26) in a girl with evidence that functional disomy of $\mathrm{X}$ material is the cause of her abnormal phenotype. Am. J. Med. Genet. A 116A: 71-76.

Aughton DJ, AlSaadi AA, Johnson JA, Transue DJ, et al. (1993). Dir dup(X) (q13 $\rightarrow$ qter) in a girl with growth retardation, microcephaly, developmental delay, seizures, and minor anomalies. Am. J. Med. Genet. 46: 159-164.

Burégio-Frota P, Valenca L, Leal GF, Duarte AR, et al. (2010). Identification of a de novo inv dup(X)(pter $\rightarrow \mathrm{q} 22)$ by multicolor banding in a girl with Turner syndrome. Genet. Mol. Res. 9: 780-784. 
Carrel L, Cottle AA, Goglin KC and Willard HF (1999). A first-generation X-inactivation profile of the human X chromosome. Proc. Natl. Acad. Sci. U. S. A. 96: 14440-14444.

Cheng SF, Rauen KA, Pinkel D, Albertson DG, et al. (2005). Xq chromosome duplication in males: clinical, cytogenetic and array CGH characterization of a new case and review. Am. J. Med. Genet. A 135: 308-313.

Incerpi MH, Miller DA, Samadi R, Settlage RH, et al. (1998). Stillbirth evaluation: what tests are needed? Am. J. Obstet. Gynecol. 178: 1121-1125.

Kokalj Vokac N, Seme Ciglenecki P, Erjavec A, Zagradisnik B, et al. (2002). Partial Xp duplication in a girl with dysmorphic features: the change in replication pattern of late-replicating dupX chromosome. Clin. Genet. 61: 54-61.

Lachlan KL, Collinson MN, Sandford RO, van Zyl B, et al. (2004). Functional disomy resulting from duplications of distal Xq in four unrelated patients. Hum. Genet. 115: 399-408.

Simpson JL and Acuna JM (2011). Genetic factors in stillbirths. Lancet 378: 878.

Solomon NM, Ross SA, Morgan T, Belsky JL, et al. (2004). Array comparative genomic hybridisation analysis of boys with X linked hypopituitarism identifies a $3.9 \mathrm{Mb}$ duplicated critical region at Xq27 containing SOX3. J. Med. Genet. 41: 669-678.

Stanton C, Lawn JE, Rahman H, Wilczynska-Ketende K, et al. (2006). Stillbirth rates: delivering estimates in 190 countries. Lancet 367: 1487-1494.

Therman E, Denniston C, Sarto GE and Ulber M (1980). X chromosome constitution and the human female phenotype. Hum. Genet. 54: 133-143.

Volletha M, Stumma M, Mohnikeb K, Kalscheuerc VM, et al. (2001). Preferential inactivation of a dupX(q23 $\rightarrow$ q27-28) chromosome in a girl with mental retardation and dysmorphy. Hum. Hered. 52: 177-182.

Zhang A, Weaver DD and Palmer CG (1997). Molecular cytogenetic identification of four X chromosome duplications. Am. J. Med. Genet. 68: 29-38. 